\title{
Economy-wide effects of reducing the time spent for water fetching and firewood collection in Ethiopia
}

\author{
Abdulaziz Mosa ${ }^{*}$, Harald Grethe ${ }^{2}$ and Khalid Siddig ${ }^{2}$
}

\begin{abstract}
Background: Water fetching and firewood collection are among home activities that are part of the daily routine of many households in rural Ethiopia. Households travel long distances and spend large amounts of time every day for collecting water and firewood. Fetching water and firewood reduce labor available for market related activities such as agriculture that affects production and productivity of these sectors negatively. Better access to water facility and energy efficient technology (such as improved stoves) is expected to release labor for market related activities that can have economy-wide impacts. The objective of this study is to investigate the economy-wide effects of access to water facility and improved stoves.

Methods: The study uses the updated 2004/05 Social Accounting Matrix (SAM) of Ethiopia. The SAM is modified to account for a detailed representation of water fetching, firewood collection and leisure activities and commodities. This study applies a single country Computable General Equilibrium (CGE) model to the updated SAM of Ethiopia. The simulation scenario is a 50\% increase in the Total Factor Productivity (TFP) of both water fetching and firewood collection activities due to better access to water infrastructure and cooking improved stoves.

Results: The findings of the study show that better access to drinking water supply and improved stoves reduces labor time spent for water fetching and firewood collection. The released labor from water fetching and firewood collection partly reallocated to leisure consumption and partly to market related activities. Those freed labors that are reallocated to marketed sectors including agricultural and non-agricultural activities leads to increase employment and enhance domestic production. Better access to drinking water and improved stoves also enhances household welfare. Households that allocate a relatively large proportion of labor to water fetching and firewood collection gain relatively more welfare. Macroeconomic indicators such as GDP, total domestic production, absorption, and imports are also positively affected due to improved access to water and energy efficient technology.
\end{abstract}

Conclusions: It is helpful to recognize the economic significance of labor released from water fetching and firewood collection in any developing economy with a limited supply of water facility and access to energy technology.

Keywords: Water fetching, Firewood collection, Computable general equilibrium model, Social accounting matrix, Total factor productivity, Ethiopia

\footnotetext{
*Correspondence: abdulazizmosa@gmail.com

1 Department of Economics, Wolkite University, P.O. Box 07, Wolkite,

Ethiopia

Full list of author information is available at the end of the article
}

\begin{abstract}
Background
Access to drinking water and household energy are among the development challenges of developing countries. Approximately, 663 million people around the world lack access to improved drinking water; out of this, $50 \%$ live in Sub-Saharan Africa. The target of the United Nation Millennium Development Goal (UNMDG) to
\end{abstract}


reduce the proportion of population without sustainable access to drinking water by half between 1990 and 2015 was unachievable by most of Sub-Saharan Africa countries but there are some on-going positive changes. However, Ethiopia is among one of the countries that successfully achieved this target. During 1990 only 13\% of the Ethiopian population had access to improved water but in 2015 half of the population is able to get improved water sources (WHO and UNICEF 2015).

However, the majority of Ethiopian households are currently unable to access drinking water close to their neighbourhood. Only $12 \%$ of the Ethiopian population has access to piped water (WHO and UNICEF 2015). The main sources of drinking water for Ethiopian households include public standpipe, protected/unprotected dug well/spring, ponds, lakes and rivers (WHO and UNICEF 2010). These sources of water are usually located far from the neighbourhood of the household. The majority of Ethiopian households often spend several hours per day for collecting drinking water from remote sources. For instance, $16 \%$ of urban and $34 \%$ of rural household on average travel between 1 and $2 \mathrm{~h}$ per trip for water fetching. In rural areas of Ethiopia, household spent a longer hours for fetching water. For example, $10 \%$ of rural household on average travel more than $2 \mathrm{~h}$ per trip for collecting water (Fig. 1).

Ethiopia is also a country where the majority of the population has limited access to electricity. More than $75 \%$ of Ethiopians live without access to electricity. Nearly all rural households and $80 \%$ of urban households in Ethiopia depend on biomass fuel for cooking (International Energy Agency 2014). Biomass fuel is sourced from firewood, animal dung, and crop residue. The majority of households use a traditional cooking stove which is less energy efficient (Rehfuess et al. 2006). Furthermore, due to underdeveloped road infrastructure and deforestation, households travel long distances and spent several hours for collecting firewood. For example, $22 \%$ and $36 \%$ of urban and rural households spent more than $2 \mathrm{~h}$ per trip to collect firewood respectively (Fig. 2).

Therefore, Ethiopian households allocate significant quantity of labor for water fetching and firewood collection activities. Furthermore, water fetchers and firewood collectors are usually agricultural laborers in Ethiopia.

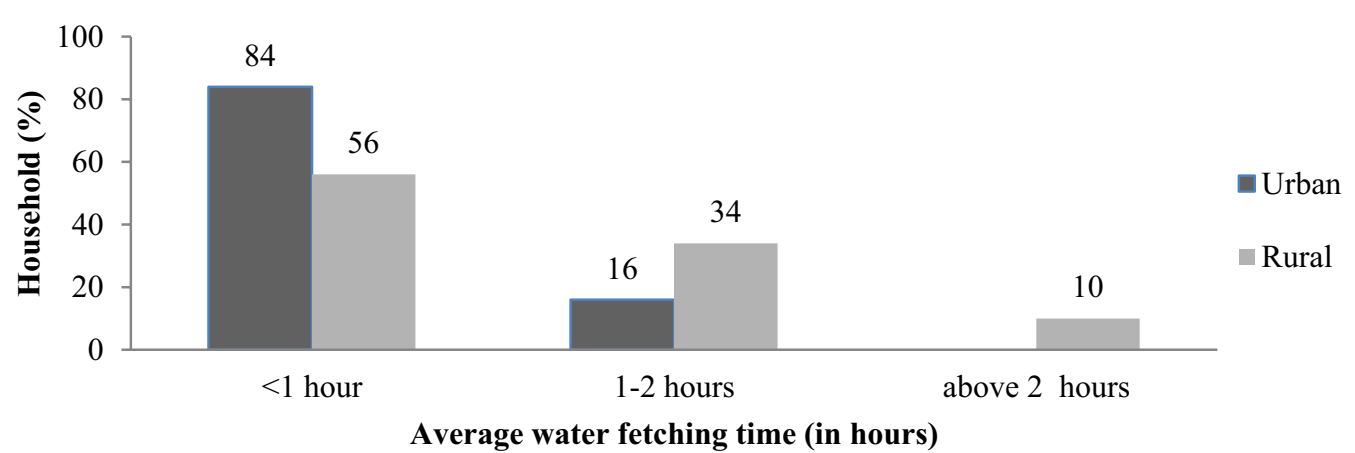

Fig. 1 Classification of Ethiopian households by water fetching time per round trip Source: Author's compilation based on Central Statistical Agency (2014)

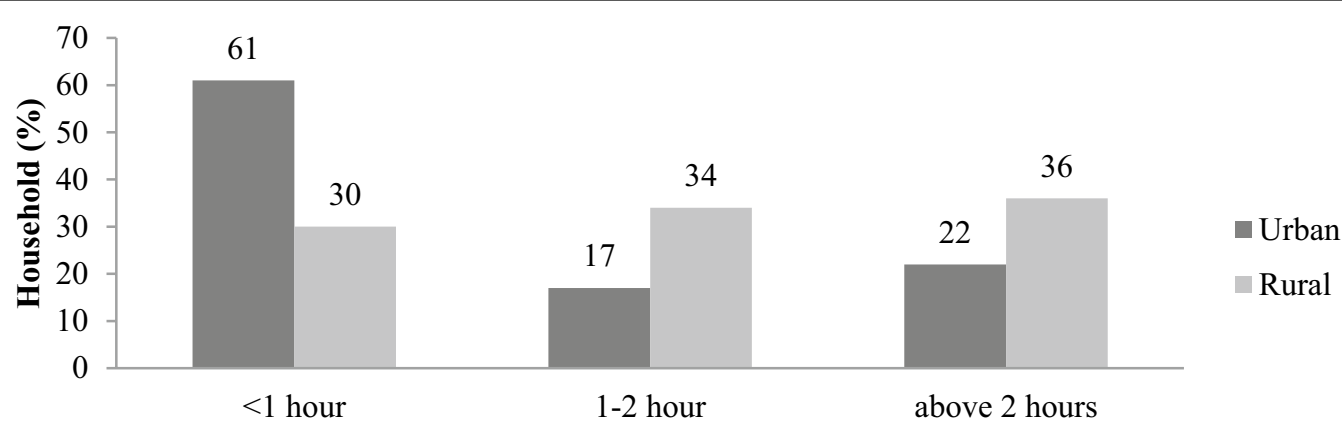

Average firewood collection time (in hours)

Fig. 2 Classification of Ethiopian households by firewood collection time per round trip Source: Author's compilation based on Central Statistical Agency (2014) 
Specifically, fetching water and firewood reduces labor time available for marketed sectors including non-agricultural activities that adversely affects production and productivity of these sectors. The time spent for fetching water and firewood can be significantly reduced through improved access to water infrastructure, and household energy saving technology (for example, improved stoves). The freed labor from water and firewood collection can be partly reallocated to marketed activities or partly reallocated to leisure. Labor reallocated to market related activities would have tremendous economy-wide implications.

Previous studies incorporate aggregate home activities including care of children and the elderly, cooking, cleaning, fetching water and collecting firewood in the CGE model such as Fontana and Wood (2000). Little or no attempts were made to distinguish between the varieties of home activities. Different types of home activities satisfy different objectives and are accomplished by different technologies. Therefore, the innovation of this study is separately depicting labor-intensive home activities such as water fetching and firewood collection and leisure into the economy wide model. The objective of this study is to investigate the economy-wide effects of better access to water facility and improved stoves.

\section{Materials and methods}

\section{Data}

This study uses the updated 2004/05 Social Accounting Matrix (SAM) of Ethiopia (Mosa 2018). The original 2005/06 SAM of Ethiopia was built by Ethiopian Development Research Institute (EDRI) in cooperation with the University of Sussex (Tebekew et al. 2009). Mosa (2018) updated the 2004/05 SAM of Ethiopia with a detailed representation of water fetching, firewood collection and leisure activities and commodities. Since water fetching and firewood collection are performed by households, distinct water fetching and firewood collection activities are added to the updated SAM in accordance with household classification. Following the approach developed by Fontana and Wood (2000) a separate activity and commodity accounts are created for leisure. Since households consume leisure, leisure activities are added to the SAM in accordance with household classification. Furthermore, distinct commodity accounts are also created for water fetching, firewood collection and leisure. Transactions for water fetching, firewood collection and leisure in the SAM are computed based on the value of labor time allocated to these activities. The values of labor time spend for water fetching, firewood collection and leisure activities are computed based on the shadow wage of labor.

The updated micro-SAM has 199 activities and 95 commodities, 34 representative household groups that are categorized by agro-ecological zones, poverty status and source of non-agricultural income, 10 labor categories that are classified by gender and occupations and 21 other factors of production such as capital and land that are differentiated by agro-ecological zones. The SAM also has 17 tax accounts and other core accounts such as government, investment and the rest of the world. The updated SAM comprises 481 row and column accounts. The updated balanced macro SAM of Ethiopia is depicted in Table 1. Furthermore, the detail micro SAM accounts is provided in Appendix 1.

\section{Model}

This study applies Static General Equilibrium (STAGE) model (McDonald 2007) to the updated SAM of Ethiopia (Mosa 2018) STAGE is a single country CGE model. It is a Social Accounting Matrix (SAM) based CGE model that has linear and non-linear relationships that govern

Table 1 Macro SAM of Ethiopia (in billions Ethiopian birr)

\begin{tabular}{|c|c|c|c|c|c|c|c|c|c|c|c|}
\hline Accounts & Commodity & Margin & Activity & Factor & Household & Gov & Tax & Enterprise & Investment & Row & Total \\
\hline Commodity & & 23.09 & 64.99 & & 162.79 & 15.91 & & & 31.89 & 16.77 & 315.45 \\
\hline Margin & 23.09 & & & & & & & & & & 23.09 \\
\hline Activity & 235.25 & & & & & & & & & & 235.25 \\
\hline Factor & & & 170.26 & & & & & & & 0.45 & 170.7 \\
\hline Household & & & & 163.80 & & 1.55 & & & & 15.79 & 181.14 \\
\hline Gov & & & & & & & 14.15 & 5.37 & & 3.73 & 23.26 \\
\hline Tax & 10.10 & & & & 2.73 & & & 1.32 & & & 14.15 \\
\hline Enterprise & & & & 6.69 & & & & & & & 6.69 \\
\hline Investment & & & & & 15.53 & 5.37 & & & 3.72 & 10.99 & 35.61 \\
\hline Row & 47.01 & & & 0.21 & 0.09 & 0.43 & & & & & 47.74 \\
\hline Total & 315.45 & 23.09 & 235.25 & 170.7 & 181.14 & 23.26 & 14.15 & 6.69 & 35.61 & 47.74 & \\
\hline
\end{tabular}

Source: Mosa (2018) 
the behavior of agents in the model. Households choose a bundle of commodities to consume in order to maximize Stone-Geary utility function. The commodities consumed by households are a composite of imported and locally produced commodities. The constant elasticity of substitution (CES) is used to combine imported and locally produced commodities by assuming that these commodities are imperfect substitutes using the Armington assumption (Armington 1969).

Several types of model specific elasticities are used in the calibration of the CGE model applied for this study. Elasticities in the model include commodity, activity and income elasticities. Commodity elasticities involve Armington's substitution elasticities between imported and domestically produced commodities and the elasticities of transformation between local commodities and export commodities. The commodity elasticities also include export demand elasticities and substitution elasticities for aggregation of commodity output. Activity elasticities cover elasticities of substitution between intermediate inputs and value added input and the substitution between different primary factors such as labor, capital and land in the nested production function. Income elasticities are elasticities for the consumption of different commodities by households. In this study, commodity, activity and Frisch elasticities are adopted from Flaig (2014). On the other hand, most of the income elasticities are adapted from Tafere et al. (2010).

\section{Policy simulations}

\section{Simulation scenarios}

The construction of drinking water infrastructure around the vicinity of households and providing access to energy technology (such as improved cooking stoves) potentially reduce the time spent on water fetching and firewood collection. This would improve the efficiency of collecting water and firewood as less labor would be required to collect the same amount of water and firewood. Therefore, this study analyses the scenario of an increase in the Total Factor Productivity (TFP) of water fetching and firewood collection activities due to improved access to drinking water and energy technology.

The quantity of labor time freed in response to better access to drinking water supply depends on agroecological zone and place of residence (rural vs. urban). This complicates the estimation of the exact amount of time saved because of improved access to drinking water infrastructure. However, the value of time saved from water fetching can be approximated in a certain range of intervals. For instance, Cook et al. (2013) in Oromia region of Ethiopia reported that improved access to water supply can successfully reduce water fetching time by $35 \%$ to over $90 \%$ per day. Accordingly, in this study, it is assumed that improved access to drinking water supply can reduce the time spent for fetching water on average by $50 \%$.

Similarly, the amount of time saved due to improved access to household energy relies on access to modern cooking technology and availability of traditional source of energy. Empirical evidence by Gaia Consulting Oy and Ethio Resource Group (2012) in Ethiopia indicates that access to improved stove reduces household's fuel consumption by more than $50 \%$. This led to approximately $50 \%$ less firewood collection time. Accordingly, in this study, it is also assumed that in response to improved access to household energy saving services (for example, improved stove), efficiency of firewood collection activities can be increased on average by $50 \%$.

Therefore, the simulation scenario is $50 \%$ increase in the TFP of both water fetching and firewood collection activities in response to improved access to water and household energy saving technology.

The cost of financing water and energy infrastructure are obtained from domestic sources or international donors (loans and grants). Specifically, the main sources of financing water and energy infrastructure in Ethiopia are government treasury, user contributions and support from international donors. Indeed, approximately three-fourth of the total national water supply budget is sourced from the treasury of government and the remaining share is covered by international donors and user contribution (World Bank 2016).

In the policy scenario, the funds for constructing drinking water and energy facilities are sourced from government savings and foreign savings (loans and grants). In other words, in order to finance the construction of water infrastructure and energy efficient technology, government savings and foreign savings are exogenously increased in the model. Since government treasury is the largest source of funds in the national water supply budget, the larger share of funds is obtained from the government savings relative to foreign savings. The total government savings are 5.4 billion birr and foreign savings are 10.9 billion birr in the updated SAM.

For approximating the effect of government expenditure on reducing water fetching and firewood collection time, expert opinions and estimates of the budget required for achieving universal water access as defined by the UNMDG are used in this study. According to experts' opinion, 0.5 to $1.5 \mathrm{~h}$ per day per household from water fetching can be saved in Sub-Saharan African countries by achieving universal access to water i.e. a $50 \%$ reduction in the share of population that is unable to secure improved drinking water (World Health Organization 2012). Therefore, for this study it is assumed that 
if Ethiopia achieved universal water access, the average water fetching time will be reduced by $50 \%$.

According to World Bank (2016), the aggregate budget required for achieving universal access to water in Ethiopia is 16.7 billion birr. The country already spent 13.6 billion birr in the year 2012. Therefore, it is assumed that an extra 3.1 (16.7-13.6) billion birr investment is needed for achieving universal water access (World Bank 2016). It is also assumed that the required fund ( 3.1 billion) is generated through a $37 \%$ increase in government savings (i.e. 2 billion birr) and a 10\% increase in foreign savings (i.e. 1.1 billion birr). Therefore, for financing water and energy infrastructure, government savings exogenously increase by $37 \%$ and foreign savings increase by $10 \%$. Since the government and foreign savings are not channelled to investments, the multiplier effects are not accounted for in this simulation.

\section{Model closure rule}

The exchange rate is flexible while the external balance is fixed in the model. The exchange rate is flexible to produce the fixed level of foreign savings for funding water infrastructure and energy efficient technology. Investment driven savings is chosen where investment is fixed and savings are flexible in the model such that savings adjust for the saving-investment balance. Alternatively, savings driven investment closure can be chosen where savings are fixed but investment is flexible to adjust the saving-investment balance to generate the required level of funds for the construction of water and energy infrastructure.

Government raises funds through income tax replacement. Government savings are fixed and income tax rates are endogenously adjusted to produce a fixed level of government savings for financing the construction of water infrastructure and energy efficient technology. Alternatively, government investment (expenditure) is fixed and income tax rates are endogenously adjusted to produce a fixed level of public expenditure for financing water and energy infrastructure. The consumer price index (CPI) is chosen as a numeraire. Furthermore, factor supplies are fixed in the model and in order to enable the mobility of water fetcher and firewood collectors across different sectors, perfect factor mobility is assumed in the model.

\section{Results and discussion}

The study examines the impact on labor reallocation across sectors, domestic production, domestic price and household consumption, household's welfare and implication on major macroeconomic indicators.

\section{Effect on labor reallocation}

In rural Ethiopia, water fetching and firewood collection is commonly accomplished by reducing the daily agricultural labor time. On the other hand, in urban parts of the country, unskilled workers commonly collect water and firewood. Water fetching and firewood collection are labor-intensive household activities. An improved TFP of water fetching and firewood collection results in reduction of labor required to perform these activities. Table 2 describes the change in labor demand across sectors in response to improved TFP of water fetching and firewood collection activities.

The simulation result indicates that because of a $50 \%$ rise in TFP, labor demand declines on average (weighted) by $22.3 \%$ for firewood collection and by $21.7 \%$ for water fetching activities. Because of better access to water facility, households consume additional water and relatively more labor is required to fetch the extra drinking water. Therefore, the labor demand for water fetching does not decline by the full $50 \%$. On the other hand, employment of labor in agriculture, industry, and service activities increases on average by $1.6 \%, 0.9 \%$ and $0.5 \%$ respectively because of absorbing the released labor from water fetching and firewood collection. The agricultural sector absorbs a larger percentage of labor relative to industry and service sectors. This happens because large shares of water fetchers and firewood collectors are agricultural laborers in Ethiopia. Thus, when water fetching and firewood collection activities are effectively accomplished, agriculture absorbs a relatively larger proportion of freed laborers relative to other sectors (such as industry and service). Furthermore, most of the freed laborers prefer to enjoy extra leisure and hence labor is reallocated to leisure $(4.6 \%)$.

\section{Effect on domestic production}

Table 3 depicts the change (weighted) in domestic production because of increased TFP of water fetching and

\begin{tabular}{|c|c|c|c|c|}
\hline Sectors & Base & Simulation & $\begin{array}{l}\text { Absolute } \\
\text { change }\end{array}$ & $\begin{array}{l}\text { \%Change } \\
\text { (weighted) }\end{array}$ \\
\hline Agriculture & 4436.54 & 4508.15 & 71.61 & 1.61 \\
\hline Industry & 258.33 & 260.60 & 2.27 & 0.88 \\
\hline Service & 1305.81 & 1312.92 & 7.11 & 0.54 \\
\hline Water fetching & 603.32 & 472.73 & -130.59 & -21.65 \\
\hline $\begin{array}{l}\text { Firewood collec- } \\
\text { tion }\end{array}$ & 537.75 & 417.61 & -120.15 & -22.34 \\
\hline Leisure & 3675.43 & 3845.35 & 169.92 & 4.62 \\
\hline
\end{tabular}

Source: Author's computation based on model results 
Table 3 Simulated changes (percentage) in domestic production by sectors

\begin{tabular}{lrrrc}
\hline Sector & Base & Simulation & $\begin{array}{l}\text { Absolute } \\
\text { change }\end{array}$ & $\begin{array}{l}\text { \%Change } \\
\text { (weighted) }\end{array}$ \\
\hline Agriculture & 7243.98 & 7331.41 & 87.43 & 1.21 \\
Industry & 3396.94 & 3416.97 & 20.03 & 0.59 \\
Service & $10,366.24$ & $10,409.66$ & 43.41 & 0.42 \\
Water fetching & 606.85 & 713.22 & 106.37 & 17.53 \\
$\begin{array}{l}\text { Firewood col- } \\
\quad \text { lection }\end{array}$ & 543.93 & 633.55 & 89.62 & 16.48 \\
Leisure & 3675.43 & 3845.35 & 169.92 & 4.62 \\
\hline
\end{tabular}

Source: Author's computation based on model results

firewood collection activities. Production of water fetching on average increases by $17.5 \%$ and firewood collection on average increases by $16.5 \%$ due to enhanced TFP. Furthermore, labor released from water fetching and firewood collection is transferred into other sectors and stimulates agricultural and non-agricultural (such as industry and services) production in the destination sector. Production of agriculture, industry and services on average increases by $1.2 \%, 0.6 \%$ and $0.4 \%$, respectively, due to employment of extra labor which is attracted from water fetching and firewood collection. Production in the agricultural sector increases by a higher proportion relative to other sectors (industry and services).

Higher TFP in water fetching and firewood collection activities provides larger proportions of released labor for agriculture relative to industry or services and hence production in this sector increases more. Furthermore, the production of leisure increases by $4.6 \%$, which is relatively greater than other sectors such as agriculture, industry, and services. This happens because there was less or no time left for leisure activities when household collects water and firewood from the distant sources and therefore, the freed labor prefers to enjoy leisure and hence more labors are reallocated to leisure. Additionally, the larger production of leisure can be explained by the fact that the consumption of leisure is more sensitive to the income changes relative to other commodities. Therefore, an increase in household income (due to reallocation of labor to income generating activities) raises the demand for leisure that leads to a more production of leisure.

\section{Effect on domestic price and household consumption}

In response to higher TFP in water fetching and firewood collection activities, a large amount of labor is released and reallocated to other activities. The labor reallocated to other sectors enhances domestic production Table 3 and at the same time results in higher income
Table 4 Simulated changes (percentage) in domestic price and household demand

\begin{tabular}{lcc}
\hline Commodities & PQD + PQS & QCD \\
\hline Agriculture & 2.10 & 1.69 \\
Industry & 2.05 & 1.32 \\
Service & 2.10 & 0.57 \\
Water fetching & -32.19 & 17.53 \\
Firewood collection & -32.10 & 16.48 \\
Leisure & 2.25 & 4.62 \\
\hline
\end{tabular}

Source: Author's computation based on model results

for households through increased factor payments. The simultaneous rise in both domestic production and household income differently affects domestic prices and household consumption. Conceptually, increased domestic production results in higher commodity supply in the market and this can potentially reduce domestic supply prices of commodities (PQS) and purchaser prices (PQD). On the other hand, the freed labor from fetching water and firewood and subsequently reallocated to marketed sectors brings extra income to the households which increases household consumption demand (QCD). This potentially increases domestic prices.

Table 4 describes the percentage change (weighted) in domestic prices and household demand in response to higher TFP in water fetching and firewood collection. The simulation results indicate that because of higher TFP in water fetching and firewood collection, QCD increases for all commodities: agricultural by $1.7 \%$, industrial by $1.3 \%$, services by $0.6 \%$, water fetching by $17.5 \%$, firewood collection by $16.5 \%$ and leisure by $4.6 \%$. Domestic prices for agricultural, industrial, and service commodities on average increase by $2.1 \%$ and for leisure commodities on average increase by $2.3 \%$. This implies that the effect of increasing income dominates the price effect. The extra income results in upward shift in households' consumption demand and hence increases domestic prices.

On the other hand, household demand for water fetching and firewood collection commodities increases but domestic prices for these commodities decrease on average by $32.2 \%$ and $32.1 \%$, respectively. Household demand for water fetching and firewood collection increases by $17.5 \%$ and $16.5 \%$ respectively. This can be explained by the fact that because of efficiency gains in water fetching and firewood collection, large quantities of water and firewood are produced and supplied to the market. Water and firewood become relatively cheaper and hence consumption demand for these commodities increases (due to income and substitution effects). 


\section{Effect on household welfare}

Increased TFP of water fetching and firewood collection also affects household welfare. Figure 3 shows the equivalent variation (EV) in percent of base income to examine the actual welfare changes across household groups. Welfare improvement happens to all groups of rural households but the amount of welfare gains varies among households. Different household groups allocate divergent quantities of labor for water fetching and firewood collection. Accordingly, welfare gains depend on household endowment of labor that can be potentially allocated to water fetching and firewood collection. In other words, households that allocate a relatively larger proportion of labor to water fetching and firewood collection obtain high welfare gains. For instance, non-poor and poor rural households in agro-ecology zones 1 and 5

\section{EV/base income}

\section{Household big urbån non-poor Hoєßehold small urban non-poor}

Household big urban poor

Household small urban poor

Household rural zone 5 non-poor non-agricultural

Household rural zone 5 non-poor mixed

Household rural zone 5 non-poor agricultural

Household rural zone 4 non-poor non-agricultural

Household rural zone 4 non-poor mixed

Household rural zone 4 non-poor agricultural

Household rural zone 3 non-poor non-agricultural

Household rural zone 3 non-poor mixed

Household rural zone 3 non-poor agricultural

Household rural zone 2 non-poor non-agricultural

Household rural zone 2 non-poor mixed

Household rural zone 2 non-poor agricultural

Household rural zone 1 non-poor non-agricultural

Household rural zone 1 non-poor mixed

Household rural zone 1 non-poor agricultural

Household rural zone 5 poor non-agricultural

Household rural zone 5 poor mixed

Household rural zone 5 poor agricultural

Household rural zone 4 poor non-agricultural

Household rural zone 4 poor mixed

Household rural zone 4 poor agricultural

Household rural zone 3 poor non-agricultural

Household rural zone 3 poor mixed

Household rural zone 3 poor agricultural

Household rural zone 2 poor non-agricultural

Household rural zone 2 poor mixed

Household rural zone 2 poor agricultural

Household rural zone 1 poor non-agricultural

Household rural zone 1 poor mixed

Household rural zone 1 poor agricultural
1.91

1.50

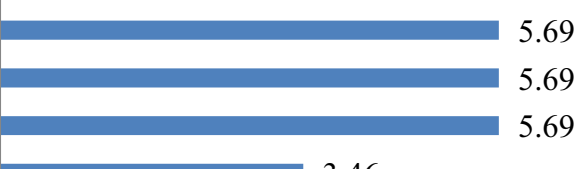

.69

3.46

3.46

3.46

3.76

3.86

3.86

3.19

3.19

3.19

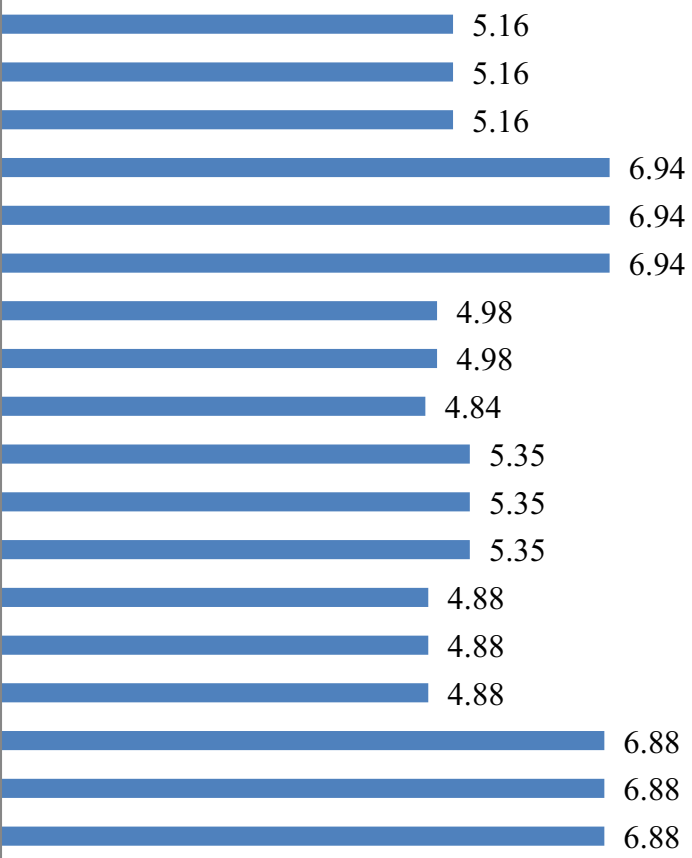

Fig. 3 Simulated changes (percentage) in household welfare (EV/base income) Source: Author's computation based on model results 
allocate the highest proportion of labor to water fetching and firewood collection relative to other groups of households. Because of increase in the TFP of water fetching and firewood collection, welfare gains by these household groups are higher than to other household groups.

On the other hand, the divergent share of water and energy consumption expenditure also results in different welfare gains across household groups. The share of consumption expenditure to water and energy commodities differs by household groups. Better access to water and energy infrastructure increases the supply of water and energy and these commodities become relatively cheaper. Households that spend a larger share of their consumption expenditure on water and energy commodities gain more welfare relative to others. For example, poor rural households located in agro-ecology zones 1 and 5 spend a larger proportion of consumption expenditure on water and energy commodities. Because of better access to water and energy facility, the welfare gains to these household groups are higher than to other household groups.

Similarly, the welfare of poor urban households is also positively affected by increasing TFP of water fetching and firewood collection. Since urban households allocate less labor for collecting water and firewood, their welfare gain is lesser than for rural households. However, the welfare of urban non-poor households is negatively affected. This can be explained by the fact that some portions of financing the construction of water and energy facility are obtained from government savings that are raised through income tax. Since urban non-poor households contribute, a larger share of tax to the government, their consumption expenditure decreases and hence welfare declines.

\section{Macroeconomic effects}

Reallocation of released labor from water fetching and firewood collection to other sectors creates economywide linkages and positively affects the macroeconomic indicators such as gross domestic product (GDP), total domestic production, absorption, import, export and exchange rate.

Figure 4 depicts the macroeconomic effect of higher TFP in water fetching and firewood collection. Total domestic production increases by $2 \%$, GDP by $2.6 \%$, absorption by $2.8 \%$, imports by $1.5 \%$ and the exchange rate by $1.3 \%$. The released labor from water fetching and firewood collection is reallocated to productive sectors that accelerate domestic production. This leads to an increase in domestic consumption (absorption) and import. Furthermore, reallocated labor promotes the growth of the economy and hence the GDP increases.

\section{Sensitivity analysis}

The sensitivity of model results due to the change in the core model parameters such as the income elasticity of leisure is discussed in this section. Specifically, this section discusses the sensitivity of labor demand, domestic production, household welfare, and major macroeconomic effects due to the change in the income elasticity of leisure. Sensitivity analysis is carried out by changing the income elasticity of leisure from 2 to 3 (50\% increase) and $4(100 \%$ increase). The sensitivity of model results in response to the change in income elasticity of leisure is provided in Appendix 2. The percentage change in labor demand and domestic production varies when the income elasticity of leisure increases from 2 to 3 and 4 . When the income elasticity of leisure is higher, a larger share of the freed labor gets into leisure and a smaller

\section{- $\%$ change}

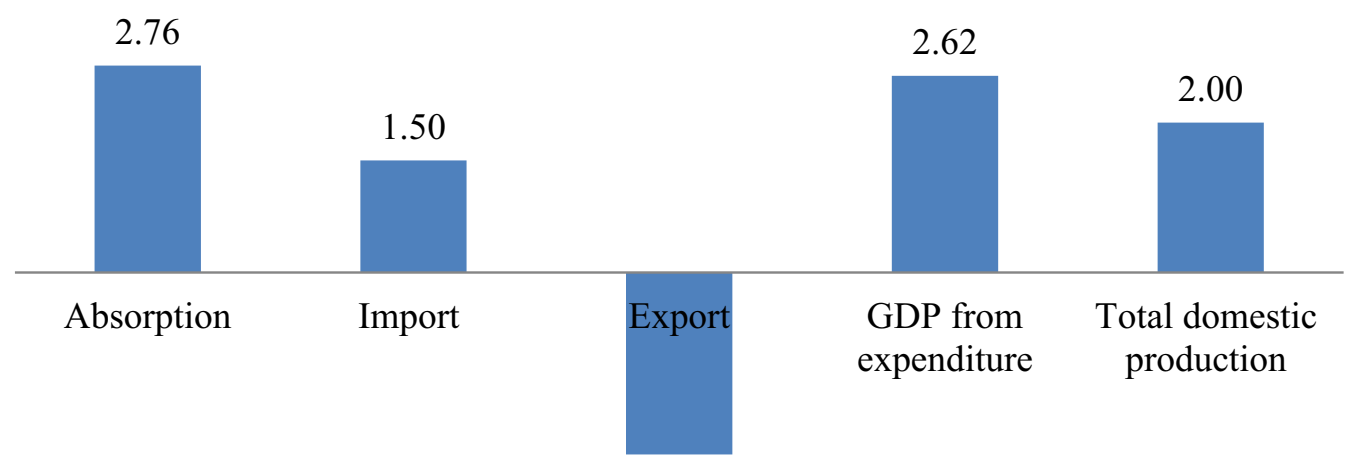

$-2.43$

Fig. 4 Macroeconomic impact (percentage changes) Source: Author's computation based on model results 
proportion is reallocated to other sectors (agriculture, industry and services) (see Appendix 2.1 for details).

Household welfare is not very sensitive to the change in the income elasticity of leisure. All groups of households except urban non-poor households have less welfare gains when the income elasticity of leisure increases from 2 to 3 and 4 (see Appendix 2.2 for the details). The reason is that leisure does not create multiplier effects through commodity demand. The macroeconomic indicators such as absorption, import demand, GDP from expenditure and total domestic production also slightly vary due to the change in the income elasticity of leisure. Specifically, absorption, import demand, GDP, and total domestic production increase by a lesser percentage when the income elasticity of leisure is higher (see Appendix 2.3 for the details).

Therefore, the change in the income elasticity of leisure leads to some changes in labor demand, domestic production, household welfare, and major macroeconomic indicators. Although the changes in the income elasticity of leisure result in slight disparities in the magnitude of simulation outcome, the direction of changes remains the same as well as the order of size.

\section{Comparison of results with previous studies}

The expansion of improved drinking water infrastructure has both costs and economic benefits. Some of the costs include investment cost (for example, cost associated with the initial construction of the water facility) and recurrent cost (for example, maintenance cost). The benefits of improved access to drinking water supply include health related benefits (for example, reduction of waterborne diseases, less mortality, avoidance of the loss of productive time due to diseases and saved health care expenditure) and the opportunity cost of travel and waiting time saved from fetching water.

The World Health Organization (WHO) estimates the benefit-cost-ratio (BCR) of universal access to improved drinking water for 136 low and middle-income countries in 2012 (World Health Organization 2012). These countries are grouped into nine sub-regions: South-Eastern Asia (S.E.Asia), Sub-Saharan Africa (SSA), Latin America and Caribbean (LAC), Southern Asia (S.Asia), Eastern Asia (E.Asia), North Africa (N.Africa), Western Asia (W.Asia), Caucasus and Central Asia (CCA) and Oceania. The BCR was estimated for individual countries initially and then it was aggregated to a region weighted by the respective country's population.

According to the WHO's study, the benefits of universal access to drinking water outweigh the costs for most of the countries (Fig. 5). Figure 5 depicts the BCR of universal access to improved drinking water across countries ranging from 0.6 in Oceania to 3.7 in S.Asia. Each additional dollar of investment provided for improved drinking water results in 0.6 to 3.7 dollar worth of benefits. The bigger proportions of these benefits are derived from the opportunity cost of labour time saved due to improved access to water supply.

On the other hand, improved access to household energy (for example, improved cooking stove) has costs and economic benefits. The costs include the purchase of stoves and installation cost among others. On the other hand, the benefits include health related benefits (reduction of diseases caused by IAP), less expenditure on health care services linked to IAP, productivity gain due to better health, time saved from cooking and fuel collection, environmental benefits (for example, fewer trees cut down). Figure 6 shows the BCR of reducing the share of the population without access to improved cooking stove

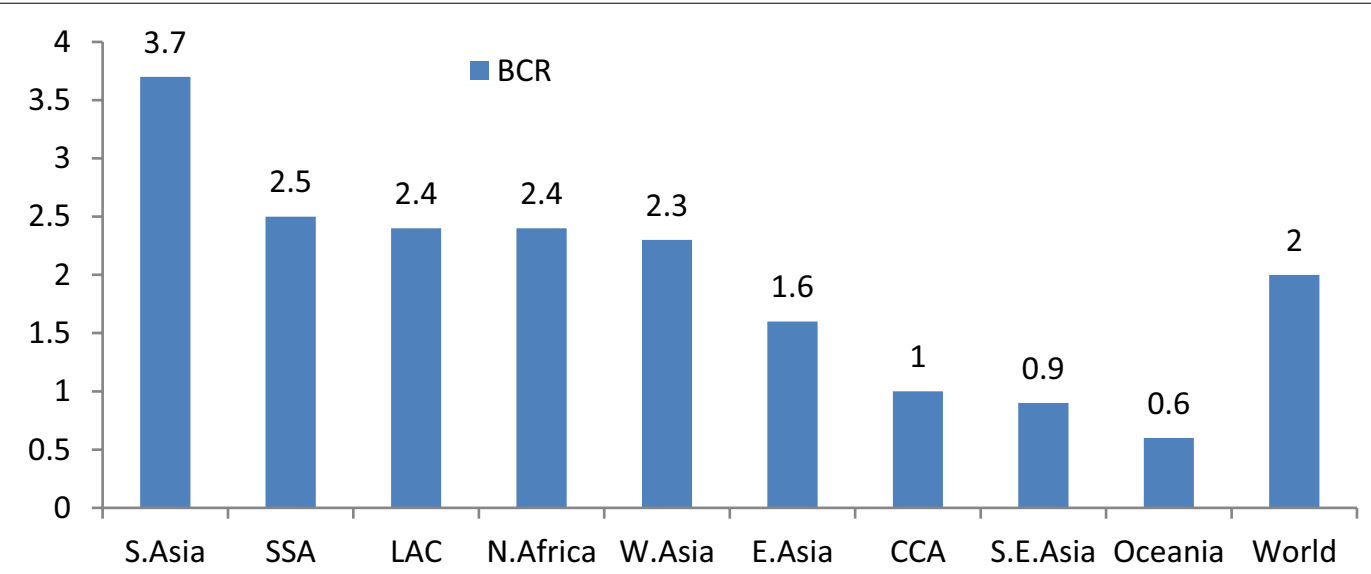

Fig. 5 BCR of improved access to water supply (US\$ return per US\$ invested) Source: Author's compilation based on World Health Organization (2012) 


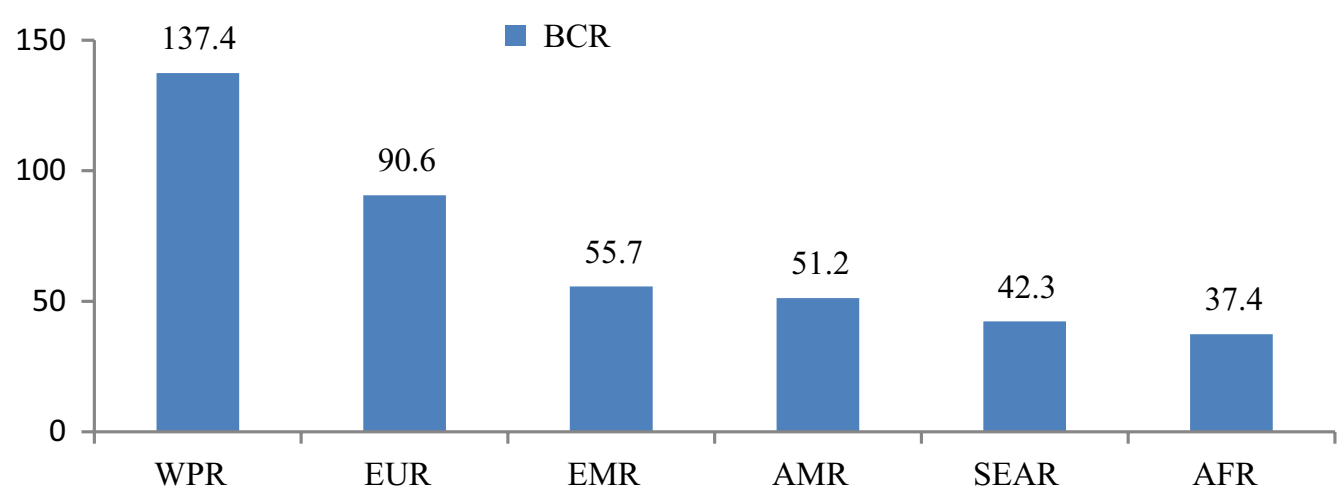

Fig. 6 BCR of access to improved stove (US\$ return per US\$ invested) Source: Author's compilation based on Hutton et al. (2006)

by $50 \%$ across WHO sub-regions. The WHO regions are South-East Asia Region (SEAR), Western Pacific Region (WPR), Eastern Mediterranean Region (EMR), and Region of the Americas (AMR), African Region (AFR) and European Region (EUR).

The estimated BCR of access to improved cooking stove varies across different sub-regions; it ranges from 37.4 to 137.4 in AFR and WPR respectively. Each additional dollar of investments to provide improved stoves results in 37.4 to 137.4 worth of US dollar benefits. The largest share of benefits is derived from the saved time that would have been used for cooking and collecting firewood (Hutton et al. 2006).

Because of the difference in the methodologies used and in the context of case study area, it is not easy to compare the result of this study with the previous studies. Although the methodology applied and the case study areas in the previous studies mentioned above are varied, this study is in consistent with the findings of the previous studies that confirm the cost of providing water facility and improved stoves outweighs the benefits gained.

\section{Conclusions}

The findings of this study show that better access to water facility and improved stoves reduces the labor time spent for water fetching and firewood collection. Those freed labor are reallocated to agricultural, non-agricultural activities and/or leisure. This lead to increase employment in all sectors, and enhances domestic production. Households also enjoy extra leisure because of better access to water and energy infrastructure and overall welfare improved. Furthermore, the released labor facilitates aggregate domestic production, consumption and imports and hence growth of the economy. Although the simulation results are sensitive to the change in the income elasticity of leisure, the direction and order of magnitude of results are unaltered in all scenarios.
Improved access to drinking water and improved stoves has health and non-health related benefits such as reduction of waterborne diseases and indoor air pollution, saved health care expenditure, productivity gain due to better health and the time saved from water fetching and firewood collection. However, this study analyzes only the benefits of freed labor from water fetching and firewood collection due to improved access to water infrastructure and improved stoves. Therefore, the economic gains of better access to water and improved stoves are only partially captured by this study.

This study used static model. A similar future work can apply dynamic model for analyzing the time path of benefits derived from investment in water supply and improved stoves. Furthermore, the precision of behavioral parameters such as elasticities in the model can be improved by estimating the value of these elasticities using econometrics.

\section{Abbreviations}

CGE: Computable General Equilibrium; CPI: Consumer price index; GDP: Gross domestic product; EV: Equivalent variation; EDRI: Ethiopian Development Research Institute; Eyleisure: Income elasticity of leisure; IEA: International Energy Agency; PQS: Domestic supply prices; PQD: Domestic purchaser prices; QCD: Household consumption demand; STAGE: Static General Equilibrium Model; SAM: Social Accounting Matrix; TFP: Total Factor Productivity; UNMDG: United Nation Millennium Development Goal; WHO: World Health Organization; UNICEF: United Nation International Children's Fund; OECD: Organization for Economic Co-operation and Development.

\section{Acknowledgements}

We are grateful to Ethiopian Development Research Institute for allowing us to access the Social Accounting Matrix of Ethiopia.

\section{Authors' contributions}

This paper is part of the corresponding author's Ph.D. dissertation. The rest authors were supervisor (HG) and co-supervisor (KS) to the corresponding author. Therefore, the corresponding author was the major contributor, the co-author contributed through discussion, reading and approving the final manuscript. All authors read and approved final manuscript.

\section{Funding}

Not applicable. 
Availability of data and materials

Some of the data used for this study can be accessed from Ethiopian Development Research Institute. Other support data can be obtained from the corresponding author up on request.

\section{Ethics approval and consent to participate}

Not applicable.

\section{Consent for publication}

Not applicable.

\section{Competing interests}

The authors declare that they have no competing interests.

\section{Author details}

${ }^{1}$ Department of Economics, Wolkite University, P.O. Box 07, Wolkite, Ethiopia.

${ }^{2}$ International Agricultural Trade and Development, Humboldt University

of Berlin, 10115 Berlin, Germany.

\section{Appendix 1: Structure of the updated 2005/06 SAM of Ethiopia \\ 1.1 Activity accounts \\ 1.1.1 Agricultural activities}

\begin{tabular}{|c|c|}
\hline Abbreviations & Descriptions \\
\hline atef1 & Growing teff in zone 1 \\
\hline atef2 & Growing teff in zone 2 \\
\hline atef3 & Growing teff in zone 3 \\
\hline atef4 & Growing teff in zone 4 \\
\hline atef5 & Growing teff in zone 5 \\
\hline abar1 & Growing barley in zone 1 \\
\hline abar2 & Growing barley in zone 2 \\
\hline abar3 & Growing barley in zone 3 \\
\hline abar4 & Growing barley in zone 4 \\
\hline abar5 & Growing barley in zone 5 \\
\hline awhea1 & Growing wheat in zone 1 \\
\hline awhea2 & Growing wheat in zone 2 \\
\hline awhea3 & Growing wheat in zone 3 \\
\hline awhea4 & Growing wheat in zone 4 \\
\hline awhea5 & Growing wheat in zone 5 \\
\hline amaiz1 & Growing maize in zone 1 \\
\hline amaiz2 & Growing maize in zone 2 \\
\hline amaiz3 & Growing maize in zone 3 \\
\hline amaiz4 & Growing maize in zone 4 \\
\hline amaiz5 & Growing maize in zone 5 \\
\hline asorg1 & Growing sorghum in zone 1 \\
\hline asorg2 & Growing sorghum in zone 2 \\
\hline asorg3 & Growing sorghum in zone 3 \\
\hline asorg4 & Growing sorghum in zone 4 \\
\hline asorg5 & Growing sorghum in zone 5 \\
\hline apul1 & Growing pulses in zone 1 \\
\hline apul2 & Growing pulses in zone 2 \\
\hline apul3 & Growing pulses in zone 3 \\
\hline apul4 & Growing pulses in zone 4 \\
\hline apul5 & Growing pulses in zone 5 \\
\hline avegfr1 & Growing vegetable and nec in zone 1 \\
\hline
\end{tabular}

\begin{tabular}{ll}
\hline Abbreviations & Descriptions \\
\hline avegfr2 & Growing vegetable and nec in zone 2 \\
avegfr3 & Growing vegetable and nec in zone 3 \\
avegfr4 & Growing vegetable and nec in zone 4 \\
avegfr5 & Growing vegetable and nec in zone 5 \\
aoils1 & Growing oil seeds in zone 1 \\
aoils2 & Growing oil seeds in zone 2 \\
aoils3 & Growing oil seeds in zone 3 \\
aoils4 & Growing oil seeds in zone 4 \\
aoils5 & Growing oil seeds in zone 5 \\
acash1 & Growing cash crops nec in zone 1 \\
acash2 & Growing cash crops nec in zone 2 \\
acash3 & Growing cash crops nec in zone 3 \\
acash4 & Growing cash crops nec in zone 4 \\
acash5 & Growing cash crops nec in zone 5 \\
aenset1 & Growing enset in zone 1 \\
aenset2 & Growing enset in zone 2 \\
aenset3 & Growing enset in zone 3 \\
aenset4 & Growing enset in zone 4 \\
aenset5 & Growing enset in zone 5 \\
acrop1 & Growing crop nec in zone 1 \\
acrop2 & Growing crop nec in zone 2 \\
acrop3 & Growing crop nec in zone 3 \\
acrop4 & Growing crop nec in zone 4 \\
acrop5 & Growing crop nec in zone 5 \\
acoff1 & Growing coffee in zone 1 \\
acoff2 & Growing coffee in zone 2 \\
acoff3 & Growing coffee in zone 3 \\
acoff4 & Growing coffee in zone 4 \\
alivst1 & Livestock farming in zone 1 \\
alivst2 & Livestock farming in zone 2 \\
alivst3 & Livestock farming in zone 3 \\
alivst4 & Livestock farming in zone 4 \\
afisfor & Livestock farming in zone 5 \\
\hline &
\end{tabular}

\subsubsection{Industrial activities}

\begin{tabular}{ll}
\hline Abbreviations & Descriptions \\
\hline $\begin{array}{l}\text { amining } \\
\text { aofood }\end{array}$ & $\begin{array}{l}\text { Mining } \\
\text { Production, processing of food and related } \\
\text { products } \\
\text { adairy }\end{array}$ \\
$\begin{array}{l}\text { Manufacturing of dairy products } \\
\text { agmillserv }\end{array}$ & Manufacturing of grain mill products \\
asug & Manufacturing of grain mill services \\
abev & Manufacturing of beverage products \\
amtob & Manufacturing of tobacco products \\
atext & Manufacturing of textile products \\
aapar & Manufacturing of wearing apparels \\
\hline
\end{tabular}




\begin{tabular}{ll}
\hline Abbreviations & Descriptions \\
\hline aleath & Manufacturing of leather products \\
awood & Manufacturing of wood and products of wood \\
apaperp & Manufacture of paper and paper products \\
achem & Chemicals products manufacturing \\
aminprod & Mineral products manufacturing \\
abmetalp & Manufacturing metal products \\
amach & Machinery manufacturing \\
aelecq & Electronic equipments manufacturing \\
aveh & Motor vehicles manufacturing \\
aomanu & Furniture and related products manufacturing \\
\hline
\end{tabular}

\subsubsection{Service activities}

\begin{tabular}{ll}
\hline Abbreviations & Descriptions \\
\hline aelect & Electricity \\
awater & Collection purification and distribution of water \\
acons & Service of construction \\
atrad & Trade \\
ahotel & Hotel \\
atrncom & Transport, communication and storage \\
afserv & Financial intermediation \\
arest & Real estate, business activities and renting \\
apadmin & Public administration \\
aeduc & Education \\
aheal & Health \\
aoserv & Business activities and related social services \\
\hline
\end{tabular}

\subsubsection{Water fetching activities}

\begin{tabular}{ll}
\hline Abbreviations & Descriptions \\
\hline awfHH-Rural_EZ1Pagr & Water fetching by HH-Rural_EZ1Pagr \\
awfHH-Rural_EZ1Pmix & Water fetching by HH-Rural_EZ1Pmix \\
awfHH-Rural_EZ1Pnagr & Water fetching by HH-Rural_EZ1Pnagr \\
awfHH-Rural_EZ2Pagr & Water fetching by HH-Rural_EZ2Pagr \\
awfHH-Rural_EZ2Pmix & Water fetching by HH-Rural_EZ2Pmix \\
awfHH-Rural_EZ2nagr & Water fetching by HH-Rural_EZ2nagr \\
awfHH-Rural_EZ3Pagr & Water fetching by HH-Rural_EZ3Pagr \\
awfHH-Rural_EZ3Pmix & Water fetching by HH-Rural_EZ3Pmix \\
awfHH-Rural_EZ3Pnagr & Water fetching by HH-Rural_EZ3Pnagr \\
awfHH-Rural_EZ4Pagr & Water fetching by HH-Rural_EZ4PPagr \\
awfHH-Rural_EZ4Pmix & Water fetching by HH-Rural_EZ4Pmix \\
awfHH-Rural_EZ4Pnagr & Water fetching by HH-Rural_EZ4Pnagr \\
awfHH-Rural_EZ5Pagr & Water fetching by HH-Rural_EZ5Pagr \\
awfHH-Rural_EZ5Pmix & Water fetching by HH-Rural_EZ5Pmix \\
awfHH-Rural_EZ5Pnagr & Water fetching by HH-Rural_EZ5Pnagr \\
awfHH-Rural_EZ1NPagr & Water fetching by HH-Rural_EZ1NPagr \\
awfHH-Rural_EZ1NPmix & Water fetching by HH-Rural_EZ1NPmix \\
awfHH-Rural_EZ1NPnagr & Water fetching by HH-Rural_EZ1NPnagr \\
\hline
\end{tabular}

\begin{tabular}{ll}
\hline Abbreviations & Descriptions \\
\hline awfHH-Rural_EZ2NPagr & Water fetching by HH-Rural_EZ2NPagr \\
awfHH-Rural_EZ2NPmix & Water fetching by HH-Rural_EZ2NPmix \\
awfHH-Rural_EZ2NPnagr & Water fetching by HH-Rural_EZ2NPnagr \\
awfHH-Rural_EZ3NPagr & Water fetching by HH-Rural_EZ3NPagr \\
awfHH-Rural_EZ3NPmix & Water fetching by HH-Rural_EZ3NPmix \\
awfHH-Rural_EZ3NPnagr & Water fetching by HH-Rural_EZ3NPnagr \\
awfHH-Rural_EZ4NPagr & Water fetching by HH-Rural_EZ4NPagr \\
awfHH-Rural_EZ4NPmix & Water fetching by HH-Rural_EZ4NPmix \\
awfHH-Rural_EZ4NPnagr & Water fetching by HH-Rural_EZ4NPnagr \\
awfHH-Rural_EZ5NPagr & Water fetching by HH-Rural_EZ5NPagr \\
awfHH-Rural_EZ5NPmix & Water fetching by HH-Rural_EZ5NPmix \\
awfHH-Rural_EZ5NPnagr & Water fetching by HH-Rural_EZ5NPnagr \\
awfHH-SmallurbanP & Water fetching by HH-SmallurbanP \\
awfHH-BigurbanP & Water fetching by HH-BigurbanP \\
awfHH-SmallurbanNP & Water fetching by HH-SmallurbanNP \\
awfHH-BigurbanNP & Water fetching by HH-BigurbanNP \\
\hline
\end{tabular}

\subsubsection{Firewood collection activities}

\begin{tabular}{cl}
\hline Abbreviations & Descriptions \\
\hline afwHH-Rural_EZ1Pagr & Firewood collection by HH-Rural_EZ1Pagr \\
afwHH-Rural_EZ1Pmix & Firewood collection by HH-Rural_EZ1Pmix \\
afwHH-Rural_EZ1Pnagr & Firewood collection by HH-Rural_EZ1Pnagr \\
afwHH-Rural_EZ2Pagr & Firewood collection by HH-Rural_EZ2Pagr \\
afwHH-Rural_EZ2Pmix & Firewood collection by HH-Rural_EZ2Pmix \\
afwHH-Rural_EZ2nagr & Firewood collection by HH-Rural_EZ2nagr \\
afwHH-Rural_EZ3Pagr & Firewood collection by HH-Rural_EZ3Pagr \\
afwHH-Rural_EZ3Pmix & Firewood collection by HH-Rural_EZ3Pmix \\
afwHH-Rural_EZ3Pnagr & Firewood collection by HH-Rural_EZ3Pnagr \\
afwHH-Rural_EZ4PPagr & Firewood collection by HH-Rural_EZ4PPagr \\
afwHH-Rural_EZ4Pmix & Firewood collection by HH-Rural_EZ4Pmix \\
afwHH-Rural_EZ4Pnagr & Firewood collection by HH-Rural_EZ4Pnagr \\
afwHH-Rural_EZ5Pagr & Firewood collection by HH-Rural_EZ5Pagr \\
afwHH-Rural_EZ5Pmix & Firewood collection by HH-Rural_EZ5Pmix \\
afwHH-Rural_EZ5Pnagr & Firewood collection by HH-Rural_EZ5Pnagr \\
afwHH-Rural_EZ1NPagr & Firewood collection by HH-Rural_EZ1NPagr \\
afwHH-Rural__ & Firewood collection by HH-Rural_EZ1NPmix \\
EZ1NPmix & \\
afwHH-Rural__ & Firewood collection by HH-Rural_EZ1NPnagr \\
EZ1NPnagr & \\
afwHH-Rural_EZ2NPagr & Firewood collection by HH-Rural_EZ2NPagr \\
afwHH-Rural__ & Firewood collection by HH-Rural_EZ2NPmix \\
EZ2NPmix & Firewood collection by HH-Rural_EZ2NNPnagr \\
afwHH-Rural_ & \\
EZ2NPnagr & Firewood collection by HH-Rural_EZ3NPmix \\
afwHH-Rural_EZ3NPagr & Firewood collection by HH-Rural_EZ3NPagr \\
afwHH-Rural__ & \\
EZ3NPmix & \\
afwHH-Rural__ & \\
EZ3NPnagr & \\
\hline
\end{tabular}




\begin{tabular}{ll}
\hline Abbreviations & Descriptions \\
\hline $\begin{array}{l}\text { afwHH-Rural_EZ4NPagr } \\
\text { afwHH-Rural_ } \\
\text { EZ4NPmix }\end{array}$ & Firewood collection by HH-Rural_EZ4NPagr \\
afwHH-Rural_ & Firewood collection by HH-Rural_EZ4NPmix \\
EZ4NPnagr & Firewood collection by HH-Rural_EZ4NPnagr \\
afwHH-Rural_EZ5NPagr & Firewood collection by HH-Rural_EZ5NPagr \\
afwHH-Rural_ & Firewood collection by HH-Rural_EZ5NPmix \\
EZ5NPmix & \\
afwHH-Rural_ & Firewood collection by HH-Rural_EZ5NPnagr \\
EZ5NPnagr & \\
afwHH-SmallurbanP & Firewood collection by HH-SmallurbanP \\
afwHH-BigurbanP & Firewood collection by HH-BigurbanP \\
afwHH-SmallurbanNP & Firewood collection by HH-SmallurbanNP \\
afwHH-BigurbanNP & Firewood collection by HH-BigurbanNP \\
\hline
\end{tabular}

\subsubsection{Leisure activities}

\begin{tabular}{ll}
\hline Abbreviations & Descriptions \\
\hline aLHH-Rural_EZ1Pagr & Leisure enjoyed by HH-Rural_EZ1Pagr \\
aLHH-Rural_EZ1Pmix & Leisure enjoyed by HH-Rural_EZ1Pmix \\
aLHH-Rural_EZ1Pnagr & Leisure enjoyed by HH-Rural_EZ1Pnagr \\
aLHH-Rural_EZ2Pagr & Leisure enjoyed by HH-Rural_EZ2Pagr \\
aLHH-Rural_EZ2Pmix & Leisure enjoyed by HH-Rural_EZ2Pmix \\
aLHH-Rural_EZ2nagr & Leisure enjoyed by HH-Rural_EZ2nagr \\
aLHH-Rural_EZ3Pagr & Leisure enjoyed by HH-Rural_EZ3Pagr \\
aLHH-Rural_EZ3Pmix & Leisure enjoyed by HH-Rural_EZ3Pmix \\
aLHH-Rural_EZ3Pnagr & Leisure enjoyed by HH-Rural_EZ3Pnagr \\
aLHH-Rural_EZ4Pagr & Leisure enjoyed by HH-Rural_EZ4Pagr \\
aLHH-Rural_EZ4Pmix & Leisure enjoyed by HH-Rural_EZ4Pmix \\
aLHH-Rural_EZ4Pnagr & Leisure enjoyed by HH-Rural_EZ4Pnagr \\
aLHH-Rural_EZ5Pagr & Leisure enjoyed by HH-Rural_EZ5Pagr \\
aLHH-Rural_EZ5Pmix & Leisure enjoyed by HH-Rural_EZ5Pmix \\
aLHH-Rural_EZ5Pnagr & Leisure enjoyed by HH-Rural_EZ5Pnagr \\
aLHH-Rural_EZ1NPagr & Leisure enjoyed by LHH-Rural_EZ1NPagr \\
aLHH-Rural_EZ1NPmix & Leisure enjoyed by HH-Rural_EZ1NPmix \\
aLHH-Rural_EZ1NPnagr & Leisure enjoyed by HH-Rural_EZ1NPnagr \\
aLHH-Rural_EZ2NPagr & Leisure enjoyed by HH-Rural_EZ2NPagr \\
aLHH-Rural_EZ2NPmix & Leisure enjoyed by HH-Rural_EZ2NPmix \\
aLHH-Rural_EZ2NPnagr & Leisure enjoyed by HH-Rural_EZ2NPnagr \\
aLHH-Rural_EZ3NPagr & Leisure enjoyed by HH-Rural_EZ3NPagr \\
aLHH-Rural_EZ3NPmix & Leisure enjoyed by HH-Rural_EZ3NPmix \\
aLHH-Rural_EZ3NPnagr & Leisure enjoyed by HH-Rural_EZ3NPnagr \\
aLHH-Rural_EZ4NPagr & Leisure enjoyed by HH-Rural_EZ4NPagr \\
aLHH-Rural_EZ4NPmix & Leisure enjoyed by HH-Rural_EZ4NPmix \\
aLHH-Rural_EZ4NPnagr & Leisure enjoyed by HH-Rural_EZ4NPnagr \\
aLHH-Rural_EZ5NPagr & Leisure enjoyed by HH-Rural_EZ5NPagr \\
aLHH-Rural_EZ5NPmix & Leisure enjoyed by HH-Rural_EZ5NPmix \\
aLHH-Rural_EZ5NPnagr & Leisure enjoyed by HH-Rural_EZ5NPnagr \\
aLHH-SmallurbanP & Leisure enjoyed by HH-SmallurbanP \\
\hline
\end{tabular}

\begin{tabular}{ll}
\hline Abbreviations & Descriptions \\
\hline aLHH-BigurbanP & Leisure enjoyed by HH-BigurbanP \\
aLHH-SmallurbanNP & Leisure enjoyed by HH-SmallurbanNP \\
aLHH-BigurbanNP & Leisure enjoyed by HH-BigurbanNP \\
\hline
\end{tabular}

\subsection{Commodity accounts}

\subsubsection{Agricultural marketed commodities}

\begin{tabular}{ll}
\hline Abbreviations & Descriptions \\
\hline ctef & Teff \\
cbar & Barley \\
cwhea & Wheat \\
cmaiz & Maize \\
csorg & Sorghum \\
cpul & Pulse \\
cveg & Vegetable \\
coils & Oil seed \\
ccotts & Cotton seed \\
ccane & Sugar cane \\
cfruit & Fruit crops \\
ctea & Tea \\
cchat & Chat \\
ccoff & Coffee \\
censet & Enset \\
ccrop & Cereal grain and other crop \\
cfiber & Plant based fiber \\
ccatt & Cattle \\
cpoul & Poultry and other small livestock \\
cmilk & Raw milk \\
ccott & Raw cotton \\
caprod & Animal product \\
cfors & Forestry products \\
cflower & Flowers \\
cfish & Fish \\
\hline
\end{tabular}

\subsubsection{Industrial marketed commodities}

\begin{tabular}{ll}
\hline Abbreviations & Descriptions \\
\hline ccoal & Coal \\
cngas & Gas \\
cmin & Minerals \\
cmeat & Meat \\
cvprod & Vegetable \\
cdairy & Dairy products \\
csug & Sugar \\
cgmill & Grain mill \\
cgmillserv & Grain mill services \\
cfood & Food \\
\hline
\end{tabular}




\begin{tabular}{ll}
\hline Abbreviations & Descriptions \\
\hline cbev & Beverages \\
ctob & Tobacco \\
cmtea & Tea manufacturing \\
cmtob & Tobacco manufacturing \\
clcott & Cotton \\
ctext & Textiles \\
capar & Wearing apparels \\
cleath & Leather \\
cwood & Wood \\
cpaper & Paper product \\
coilptrl & Petroleum coal \\
cfert & Fertilizers \\
cchem & Chemicals \\
cminprod & Mineral \\
cmetal & Metals \\
cmprod & Products of metal \\
cveh & Motor vehicles \\
celecq & Electronic equipment \\
cmach & Machinery \\
comanu & Products of manufacturing \\
\hline
\end{tabular}

\subsubsection{Marketed services}

\begin{tabular}{ll}
\hline Abbreviations & Descriptions \\
\hline cfruito & Fruit crops \\
csorgo & Sorghum \\
ctefo & Teff \\
cpulo & Pulses \\
ccaneo & Sugar cane \\
cchato & Chat \\
ccoffo & Coffee \\
censeto & Enset \\
ccropo & Grains \\
cpoulo & Poultry \\
cmilko & Raw milk \\
ccotto & Raw cotton \\
\hline
\end{tabular}

\subsubsection{Home consumed processed (industrial) commodities}

\begin{tabular}{ll}
\hline Abbreviations & Descriptions \\
\hline caprodo & Animal products \\
cforso & Products of forestry \\
cfisho & Fish \\
cmeato & Meat \\
cdairyo & Dairy products \\
\hline
\end{tabular}

\begin{tabular}{ll}
\hline Abbreviations & Descriptions \\
\hline celect & Electricity \\
cwater & Water \\
ccons & Construction \\
ctrad & Trade \\
chotel & Hotel \\
ctrans & Transport service \\
ccomm & Communication \\
cfserv & Financial service \\
cbserv & Business service \\
cpadmin & Public administration \\
ceduc & Education \\
cheal & Health \\
coserv & Recreation and others \\
crest & Real estate and renting services \\
\hline
\end{tabular}

\subsubsection{Home consumed agricultural commodities}

\begin{tabular}{ll}
\hline Abbreviations & Descriptions \\
\hline cmaizo & Maize \\
coilso & Oil seed \\
cvego & Vegetable \\
cwheao & Wheat \\
cbaro & Barley \\
\hline
\end{tabular}

\subsubsection{Home consumed service commodities}

\begin{tabular}{ll}
\hline Abbreviations & Descriptions \\
\hline cresto & Housing \\
\hline
\end{tabular}

\subsubsection{Water fetching commodities}

\begin{tabular}{ll}
\hline Abbreviations & Descriptions \\
\hline cwfHH-Rural_EZ1Pagr & Water consumed by HH-Rural_EZ1Pagr \\
cwfHH-Rural_EZ1Pmix & Water consumed by HH-Rural_EZ1Pmix \\
cwfHH-Rural_EZ1Pnagr & Water consumed by HH-Rural_EZ1Pnagr \\
cwfHH-Rural_EZ2Pagr & Water consumed by HH-Rural_EZ2Pagr \\
cwfHH-Rural_EZ2Pmix & Water consumed by HH-Rural_EZ2Pmix \\
cwfHH-Rural_EZ2nagr & Water consumed by HH-Rural_EZ2nagr \\
cwfHH-Rural_EZ3Pagr & Water consumed by HH-Rural_EZ3Pagr \\
cwfHH-Rural_EZ3Pmix & Water consumed by HH-Rural_EZ3Pmix \\
cwfHH-Rural_EZ3Pnagr & Water consumed by HH-Rural_EZ3Pnagr \\
cwfHH-Rural_EZ4Pagr & Water consumed by HH-Rural_EZ4Pagr \\
cwfHH-Rural_EZ4Pmix & Water consumed by HH-Rural_EZ4Pmix \\
cwfHH-Rural_EZ4Pnagr & Water consumed by HH-Rural_EZ4Pnagr \\
cwfHH-Rural_EZ5Pagr & Water consumed by HH-Rural_EZ5Pagr \\
cwfHH-Rural_EZ5Pmix & Water consumed by HH-Rural_EZ5Pmix \\
cwfHH-Rural_EZ5Pnagr & Water consumed by HH-Rural_EZ5Pnagr \\
\hline
\end{tabular}




\begin{tabular}{ll}
\hline Abbreviations & Descriptions \\
\hline cwfHH-Rural_EZ1NPagr & Water consumed by HH-Rural_EZ1NPagr \\
cwfHH-Rural_EZ1NPmix & Water consumed by HH-Rural_EZ1NPmix \\
cwfHH-Rural_EZ1NPnagr & Water consumed by HH-Rural_EZ1NPnagr \\
cwfHH-Rural_EZ2NPagr & Water consumed by HH-Rural_EZ2NPagr \\
cwfHH-Rural_EZ2NPmix & Water consumed by HH-Rural_EZ2NPmix \\
cwfHH-Rural_EZ2NPnagr & Water consumed by HH-Rural_EZ2NPnagr \\
cwfHH-Rural_EZ3NPagr & Water consumed by HH-Rural_EZ3NPagr \\
cwfHH-Rural_EZ3NPmix & Water consumed by HH-Rural_EZ3NPmix \\
cwfHH-Rural_EZ3NPnagr & Water consumed by HH-Rural_EZ3NPnagr \\
cwfHH-Rural_EZ4NPagr & Water consumed by HH-Rural_EZ4NPagr \\
cwfHH-Rural_EZ4NPmix & Water consumed by HH-Rural_EZ4NPmix \\
cwfHH-Rural_EZ4NPnagr & Water consumed by HH-Rural_EZ4NPnagr \\
cwfHH-Rural_EZ5NPagr & Water consumed by HH-Rural_EZ5NPagr \\
cwfHH-Rural_EZ5NPmix & Water consumed by HH-Rural_EZ5NPmix \\
cwfHH-Rural_EZ5NPnagr & Water consumed by HH-Rural_EZ5NPnagr \\
cwfHH-SmallurbanP & Water consumed by HH-SmallurbanP \\
cwfHH-BigurbanP & Water consumed by HH-BigurbanP \\
cwfHH-SmallurbanNP & Water consumed by HH-SmallurbanNP \\
cwfHH-BigurbanNP & Water consumed by HH-BigurbanNP \\
\hline
\end{tabular}

\subsection{8: Firewood collection commodities}

\begin{tabular}{lc}
\hline Abbreviations & Descriptions \\
\hline cfwHH-Rural_EZ1Pagr & Firewood consumed by HH-Rural_ \\
& EZ1Pagr \\
cfwHH-Rural_EZ1Pmix & Firewood consumed by HH-Rural_ \\
& EZ1Pmix \\
cfwHH-Rural_EZ1Pnagr & Firewood consumed by HH-Rural_ \\
& EZ1Pnagr \\
cfwHH-Rural_EZ2Pagr & Firewood consumed by HH-Rural_ \\
& EZ2Pagr \\
cfwHH-Rural_EZ2Pmix & Firewood consumed by HH-Rural_ \\
& EZ2Pmix \\
cfwHH-Rural_EZ2nagr & Firewood consumed by HH-Rural_ \\
& EZ2nagr \\
cfwHH-Rural_EZ3Pagr & Firewood consumed by HH-Rural_ \\
& EZ3Pagr \\
cfwHH-Rural_EZ3Pmix & Firewood consumed by HH-Rural_ \\
& EZ3Pmix \\
cfwHH-Rural_EZ3Pnagr & Firewood consumed by HH-Rural_ \\
& EZ3Pnagr \\
cfwHH-Rural_EZ4Pagr & Firewood consumed by HH-Rural_ \\
& EZ4Pagr \\
cfwHH-Rural_EZ4Pmix & Firewood consumed by HH-Rural_ \\
cfwHH-Rural_EZ4Pnagr & EZ4Pmix \\
& Firewood consumed by HH-Rural_ \\
cfwHH-Rural_EZ5Pagr & EZ4Pnagr \\
& Firewood consumed by HH-Rural_ \\
cfwHH-Rural_EZ5Pmix & EZ5Pagr \\
& Firewood consumed by HH-Rural_ \\
\hline & EZ5Pmix \\
\hline
\end{tabular}

\begin{tabular}{|c|c|}
\hline Abbreviations & Descriptions \\
\hline cfwHH-Rural_EZ5Pnagr & $\begin{array}{l}\text { Firewood consumed by HH-Rural_ } \\
\text { EZ5Pnagr }\end{array}$ \\
\hline cfwHH-Rural_EZ1NPagr & $\begin{array}{l}\text { Firewood consumed by HH-Rural_ } \\
\text { EZ1NPagr }\end{array}$ \\
\hline cfwHH-Rural_EZ1NPmix & $\begin{array}{l}\text { Firewood consumed by HH-Rural_ } \\
\text { EZ1NPmix }\end{array}$ \\
\hline cfwHH-Rural_EZ1NPnagr & $\begin{array}{l}\text { Firewood consumed by HH-Rural_ } \\
\text { EZ1NPnagr }\end{array}$ \\
\hline cfwHH-Rural_EZ2NPagr & $\begin{array}{l}\text { Firewood consumed by HH-Rural_ } \\
\text { EZ2NPagr }\end{array}$ \\
\hline cfwHH-Rural_EZ2NPmix & $\begin{array}{l}\text { Firewood consumed by HH-Rural_ } \\
\text { EZ2NPmix }\end{array}$ \\
\hline cfwHH-Rural_EZ2NPnagr & $\begin{array}{l}\text { Firewood consumed by HH-Rural_ } \\
\text { EZ2NPnagr }\end{array}$ \\
\hline cfwHH-Rural_EZ3NPagr & $\begin{array}{l}\text { Firewood consumed by HH-Rural_ } \\
\text { EZ3NPagr }\end{array}$ \\
\hline cfwHH-Rural_EZ3NPmix & $\begin{array}{l}\text { Firewood consumed by HH-Rural_ } \\
\text { EZ3NPmix }\end{array}$ \\
\hline cfwHH-Rural_EZ3NPnagr & $\begin{array}{l}\text { Firewood consumed by HH-Rural_ } \\
\text { EZ3NPnagr }\end{array}$ \\
\hline cfwHH-Rural_EZ4NPagr & $\begin{array}{l}\text { Firewood consumed by HH-Rural_ } \\
\text { EZ4NPagr }\end{array}$ \\
\hline cfwHH-Rural_EZ4NPmix & $\begin{array}{l}\text { Firewood consumed by HH-Rural_ } \\
\text { EZ4NPmix }\end{array}$ \\
\hline cfwHH-Rural_EZ4NPnagr & $\begin{array}{l}\text { Firewood consumed by HH-Rural_ } \\
\text { EZ4NPnagr }\end{array}$ \\
\hline cfwHH-Rural_EZ5NPagr & $\begin{array}{l}\text { Firewood consumed by HH-Rural_ } \\
\text { EZ5NPagr }\end{array}$ \\
\hline cfwHH-Rural_EZ5NPmix & $\begin{array}{l}\text { Firewood consumed by HH-Rural_ } \\
\text { EZ5NPmix }\end{array}$ \\
\hline cfwHH-RuralE_Z5NPnagr & $\begin{array}{l}\text { Firewood consumed by HH-Rural_ } \\
\text { EZ5NPnagr }\end{array}$ \\
\hline cfwHH-SmallurbanP & $\begin{array}{l}\text { Firewood consumed by HH-Smal- } \\
\text { lurbanP }\end{array}$ \\
\hline cfwHH-BigurbanP & $\begin{array}{l}\text { Firewood consumed by } \mathrm{HH} \text {-Bigur- } \\
\text { banP }\end{array}$ \\
\hline cfwHH-SmallurbanNP & $\begin{array}{l}\text { Firewood consumed by HH-Small- } \\
\text { urbanNP }\end{array}$ \\
\hline cfwHH-BigurbanNP & $\begin{array}{l}\text { Firewood consumed by HH-Bigur- } \\
\text { banNP }\end{array}$ \\
\hline
\end{tabular}

\subsubsection{Leisure commodities}

\begin{tabular}{ll}
\hline Abbreviations & Descriptions \\
\hline CLHH-Rural_EZ1Pagr & Leisure enjoyed by HH-Rural_EZ1Pagr \\
CLHH-Rural_EZ1Pmix & Leisure enjoyed by HH-Rural_EZ1Pmix \\
CLHH-Rural_EZ1Pnagr & Leisure enjoyed by HH-Rural_EZ1Pnagr \\
CLHH-Rural_EZ2Pagr & Leisure enjoyed by HH-Rural_EZ2Pagr \\
CLHH-Rural_EZ2Pmix & Leisure enjoyed by HH-Rural_EZ2Pmix \\
CLHH-Rural_EZ2nagr & Leisure enjoyed by HH-Rural_EZ2nagr \\
CLHH-Rural_EZ3Pagr & Leisure enjoyed by HH-Rural_EZ3Pagr \\
CLHH-Rural_EZ3Pmix & Leisure enjoyed by HH-Rural_EZ3Pmix \\
CLHH-Rural_EZ3Pnagr & Leisure enjoyed by HH-Rural_EZ3Pnagr \\
\hline
\end{tabular}




\begin{tabular}{ll}
\hline Abbreviations & Descriptions \\
\hline CLHH-Rural_EZ4Pagr & Leisure enjoyed by HH-Rural_EZ4Pagr \\
CLHH-Rural_EZ4Pmix & Leisure enjoyed by HH-Rural_EZ4Pmix \\
CLHH-Rural_EZ4Pnagr & Leisure enjoyed by HH-Rural_EZ4Pnagr \\
CLHH-Rural_EZ5Pagr & Leisure enjoyed by HH-Rural_EZ5Pagr \\
CLHH-Rural_EZ5Pmix & Leisure enjoyed by HH-Rural_EZ5Pmix \\
CLHH-Rural_EZ5Pnagr & Leisure enjoyed by HH-Rural_EZ5Pnagr \\
CLHH-Rural_EZ1NPagr & Leisure enjoyed by HH-Rural_EZ1NPagr \\
CLHH-Rural_EZ1NPmix & Leisure enjoyed by HH-Rural_EZ1NPmix \\
CLHH-Rural_EZ1NPnagr & Leisure enjoyed by HH-Rural_EZ1NPnagr \\
CLHH-Rural_EZ2NPagr & Leisure enjoyed by HH-Rural_EZ2NPagr \\
CLHH-Rural_EZ2NPmix & Leisure enjoyed by HH-Rural_EZ2NPmix \\
CLHH-Rural_EZ2NPnagr & Leisure enjoyed by HH-Rural_EZ2NPnagr \\
CLHH-Rural_EZ3NPagr & Leisure enjoyed by HH-Rural_EZ3NPagr \\
CLHH-Rural_EZ3NPmix & Leisure enjoyed by HH-Rural_EZ3NPmix \\
CLHH-Rural_EZ3NPnagr & Leisure enjoyed by HH-Rural_EZ3NPnagr \\
CLHH-Rural_EZ4NPagr & Leisure enjoyed by HH-Rural_EZ4NPagr \\
CLHH-Rural_EZ4NPmix & Leisure enjoyed by HH-Rural_EZ4NPmix \\
CLHH-Rural_EZ4NPnagr & Leisure enjoyed by HH-Rural_EZ4NPnagr \\
CLHH-Rural_EZ5NPagr & Leisure enjoyed by HH-Rural_EZ5NPagr \\
CLHH-Rural_EZ5NPmix & Leisure enjoyed by HH-Rural_EZ5NPmix \\
CLHH-Rural_EZ5NPnagr & Leisure enjoyed by HH-Rural_EZ5NPnagr \\
CLHH-SmallurbanP & Leisure enjoyed by HH-SmallurbanP \\
cLHH-BigurbanP & Leisure enjoyed by HH-BigurbanP \\
CLHH-SmallurbanNP & Leisure enjoyed by HH-SmallurbanNP \\
CLHH-BigurbanNP & Leisure enjoyed by HH-BigurbanNP \\
& \\
&
\end{tabular}

\subsection{Household accounts}

\begin{tabular}{|c|c|}
\hline Abbreviations & Descriptions \\
\hline HH-Rural_EZ1Pagr & $\begin{array}{l}\text { Household rural zone } 1 \text { poor } \\
\text { agricultural }\end{array}$ \\
\hline HH-Rural_EZ1Pmix & Household rural zone 1 poor mixed \\
\hline HH-Rural_EZ1Pnagr & $\begin{array}{l}\text { Household rural zone } 1 \text { poor non- } \\
\text { agricultural }\end{array}$ \\
\hline HH-Rural_EZ2Pagr & $\begin{array}{l}\text { Household rural zone } 2 \text { poor } \\
\text { agricultural }\end{array}$ \\
\hline HH-Rural_EZ2Pmix & Household rural zone 2 poor mixed \\
\hline HH-Rural_EZ2nagr & $\begin{array}{l}\text { Household rural zone } 2 \text { poor non- } \\
\text { agricultural }\end{array}$ \\
\hline HH-Rural_EZ3Pagr & $\begin{array}{l}\text { Household rural zone } 3 \text { poor } \\
\text { agricultural }\end{array}$ \\
\hline HH-Rural_EZ3Pmix & Household rural zone 3 poor mixed \\
\hline HH-Rural_EZ3Pnagr & $\begin{array}{l}\text { Household rural zone } 3 \text { poor non- } \\
\text { agricultural }\end{array}$ \\
\hline HH-Rural_EZ4Pagr & $\begin{array}{l}\text { Household rural zone } 4 \text { poor } \\
\text { agricultural }\end{array}$ \\
\hline HH-Rural_EZ4Pmix & Household rural zone 4 poor mixed \\
\hline HH-Rural_EZ4Pnagr & $\begin{array}{l}\text { Household rural zone } 4 \text { poor non- } \\
\text { agricultural }\end{array}$ \\
\hline HH-Rural_EZ5Pagr & $\begin{array}{l}\text { Household rural zone } 5 \text { poor } \\
\text { agricultural }\end{array}$ \\
\hline
\end{tabular}

\begin{tabular}{ll}
\hline Abbreviations & Descriptions \\
\hline HH-Rural_EZ5Pmix & Household rural zone 5 poor mixed \\
HH-Rural_EZ5Pnagr & $\begin{array}{c}\text { Household rural zone } 5 \text { poor non- } \\
\text { agricultural }\end{array}$ \\
Household rural zone 1 non-poor \\
agricultural \\
Household rural zone 1 non-poor \\
mixed
\end{tabular}

1.4 Factor accounts

1.4.1 Labor accounts

\begin{tabular}{ll}
\hline Abbreviations & Descriptions \\
\hline Agrm & Agricultural labor male \\
Agrf & Agricultural labor female \\
Admm & Administrative labor male \\
Admf & Administrative labor female \\
Profm & Professional labor male \\
Proff & Professional labor female \\
Unskm & Unskilled labor male \\
Unskf & Unskilled labor female \\
Skm & Skilled labor male \\
Skf & Skilled labor female \\
\hline
\end{tabular}




\subsubsection{Non-labor factors}

\begin{tabular}{ll}
\hline Abbreviations & Descriptions \\
\hline Capital_Land_RuralEZ1P & Capital land for rural poor in zone 1 \\
Capital_Land_RuralEZ1NP & Capital land for rural non-poor in zone 1 \\
Capital_Land_RuralEZ2P & Capital land for rural poor in zone 2 \\
Capital_Land_RuralEZ2NP & Capital land for rural non-poor in zone 2 \\
Capital_Land_RuralEZ3P & Capital land for rural poor in zone 3 \\
Capital_Land_RuralEZ3NP & Capital land for rural non-poor in zone 3 \\
Capital_Land_RuralEZ4P & Capital land for rural poor in zone 4 \\
Capital_Land_RuralEZ4NP & Capital land for rural non-poor in zone 4 \\
Capital_Land_RuralEZ5P & Capital land for rural poor in zone 5 \\
Capital_Land_RuralEZ5NP & Capital land for rural non-poor in zone 5 \\
Capital_Livst_RuralEZ1P & Capital livestock for rural poor in zone 1 \\
Capital_Livst_RuralEZ1NP & Capital livestock for rural non-poor in zone 1 \\
Capital_Livst_RuralEZ2P & Capital livestock for rural poor in zone 2 \\
Capital_Livst_RuralEZ2NP & Capital livestock for rural non-poor in zone 2 \\
Capital_Livst_RuralEZ3P & Capital livestock for rural poor in zone 3 \\
Capital_Livst_RuralEZ3NP & Capital livestock for rural non-poor in zone 3 \\
Capital_Livst_RuralEZ4P & Capital livestock for rural poor in zone 4 \\
Capital_Livst_RuralEZ4NP & Capital livestock for rural non-poor in zone 4 \\
Capital_Livst_RuralEZ5P & Capital livestock for rural poor in zone 5 \\
Capital_Livst_RuralEZ5NP & Capital livestock for rural non-poor in zone 5 \\
Non_Agg_capital & Non-agricultural capital \\
\hline
\end{tabular}

\subsection{Other accounts}

\begin{tabular}{ll}
\hline Abbreviations & Descriptions \\
\hline ENT & Enterprises \\
GOVT & Government \\
TotalMargin & Transport margins \\
DSTOC & Stock changes \\
KAP & Savings \\
ROW & Rest of the world \\
\hline
\end{tabular}

\subsection{Tax accounts}

\begin{tabular}{ll}
\hline Abbreviations & Descriptions \\
\hline LandTx & Land use tax \\
CapGainTx & Capital gains tax \\
IntIncTax & Interest income tax \\
RentIncTx & Rental income tax \\
DivTx & Dividend tax \\
ProfitTx & Profit tax \\
AglncTx & Income tax (agricultural) \\
HHIncTx & Income tax (personal) \\
OEntTx & Other direct taxes \\
Impsur & Surtax from import \\
\hline
\end{tabular}

\begin{tabular}{ll}
\hline Abbreviations & Descriptions \\
\hline ImpVAT & Value added tax from import \\
ImpEcsTx & Excise tax from import \\
ImpWTx & Import withholding tax \\
ImpDuty & Import tax \\
ServTx & Service tax \\
LocEcsTX & Domestic excise tax \\
LocalVAT & Domestic value added tax \\
\hline
\end{tabular}

\section{Appendix 2: Sensitivity of model results to changes in the income elasticity of leisure}

\subsection{Sensitivity of labor demand and production (percentage)}

\begin{tabular}{llll}
\hline $\begin{array}{l}\text { Labor demand } \\
\text { by activities }\end{array}$ & Eyleisure ${ }^{*} \mathbf{2}$ & Eyleisure= & Eyleisure= \\
\hline Agriculture & 1.61 & 1.16 & 0.82 \\
Industry & 0.88 & 1.07 & 1.28 \\
Service & 0.54 & 0.81 & 1.10 \\
Water fetching & -21.65 & -23.56 & -24.91 \\
Firewood collection & -22.35 & -24.13 & -25.39 \\
Leisure & 4.62 & 5.63 & 6.34 \\
Production by activities & Eyleisure $=2$ & Eyleisure $=3$ & Eyleisure =4 \\
Agriculture & 1.21 & 0.89 & 0.65 \\
Industry & 0.59 & 0.61 & 0.63 \\
Service & 0.42 & 0.48 & 0.55 \\
Water fetching & 17.53 & 14.66 & 12.64 \\
Firewood collection & 16.48 & 13.81 & 11.91 \\
Leisure & 4.62 & 5.63 & 6.34 \\
\hline
\end{tabular}

Source: Author's computation based on model results

*Eyleisure: refers to the income elasticity of leisure

\subsection{Sensitivity of welfare (EV/base income) to changes in the income elasticity of leisure}

\begin{tabular}{lccc}
\hline Households & Eyleisure $=\mathbf{2}$ & Eyleisure $=\mathbf{3}$ & Eyleisure $=\mathbf{4}$ \\
\hline HH-Rural_EZ1Pagr & 6.88 & 6.82 & 6.80 \\
HH-Rural_EZ1Pmix & 6.88 & 6.82 & 6.80 \\
HH-Rural_EZ1Pnagr & 6.88 & 6.82 & 6.80 \\
HH-Rural_EZ2Pagr & 4.88 & 4.89 & 4.91 \\
HH-Rural_EZ2Pmix & 4.88 & 4.89 & 4.91 \\
HH-Rural_EZ2nagr & 4.88 & 4.89 & 4.91 \\
HH-Rural_EZ3Pagr & 5.35 & 5.34 & 5.34 \\
HH-Rural_EZ3Pmix & 5.35 & 5.34 & 5.34 \\
HH-Rural_EZ3Pnagr & 5.35 & 5.34 & 5.34 \\
HH-Rural_EZ4Pagr & 4.84 & 4.85 & 4.86 \\
HH-Rural_EZ4Pmix & 4.98 & 4.96 & 4.95 \\
HH-Rural_EZ4Pnagr & 4.98 & 4.96 & 4.95 \\
HH-Rural_EZ5Pagr & 6.94 & 6.76 & 6.64 \\
\hline
\end{tabular}




\begin{tabular}{lccc}
\hline Households & Eyleisure $=\mathbf{2}$ & Eyleisure $=\mathbf{3}$ & Eyleisure $=\mathbf{4}$ \\
\hline HH-Rural_EZ5Pmix & 6.94 & 6.76 & 6.64 \\
HH-Rural_EZ5Pnagr & 6.94 & 6.76 & 6.64 \\
HH-Rural_EZ1NPagr & 5.16 & 5.12 & 5.10 \\
HH-Rural_EZ1NPmix & 5.16 & 5.12 & 5.10 \\
HH-Rural_EZ1NPnagr & 5.16 & 5.12 & 5.10 \\
HH-Rural_EZ2NPagr & 3.19 & 3.16 & 3.13 \\
HH-Rural_EZ2NPmix & 3.19 & 3.16 & 3.13 \\
HH-Rural_EZ2NPnagr & 3.19 & 3.16 & 3.13 \\
HH-Rural_EZ3NPagr & 3.86 & 3.83 & 3.82 \\
HH-Rural_EZ3NPmix & 3.86 & 3.83 & 3.82 \\
HH-Rural_EZ3NPnagr & 3.76 & 3.75 & 3.74 \\
HH-Rural_EZ4NPagr & 3.46 & 3.41 & 3.37 \\
HH-Rural_EZ4NPmix & 3.46 & 3.41 & 3.37 \\
HH-Rural_EZ4NPnagr & 3.46 & 3.41 & 3.37 \\
HH-Rural_EZ5NPagr & 5.69 & 5.52 & 5.40 \\
HH-Rural_EZ5NPmix & 5.69 & 5.52 & 5.40 \\
HH-Rural_EZ5NPnagr & 5.69 & 5.52 & 5.40 \\
HH-SmallurbanP & 1.50 & 1.31 & 1.12 \\
HH-BigurbanP & 1.91 & 1.85 & 1.80 \\
HH-SmallurbanNP & -3.75 & -4.03 & -4.28 \\
HH-BigurbanNP & -1.54 & -1.72 & -1.89 \\
\hline Source:Aunhor's CO5 & & & \\
\hline
\end{tabular}

Source: Author's computation based on model results

\subsection{Sensitivity of macroeconomic effects (percentage) to changes in the income elasticity of leisure}

\begin{tabular}{llll}
\hline $\begin{array}{l}\text { Real macroeconomic } \\
\text { indicators }\end{array}$ & Eyleisure $=\mathbf{2}$ & Eyleisure $=\mathbf{3}$ & Eyleisure $=\mathbf{4}$ \\
\hline Absorption & 2.76 & 2.64 & 2.67 \\
\hline Import & 1.50 & 1.43 & 1.38 \\
GDP from expenditure & 2.62 & 2.56 & 2.52 \\
$\begin{array}{l}\text { Total domestic produc- } \\
\text { tion }\end{array}$ & 2.00 & 1.96 & 1.93 \\
\hline
\end{tabular}

\section{Source: Author's computation based on model results}

Received: 21 July 2020 Accepted: 19 September 2020

Published online: 24 September 2020

\section{References}

Armington PS (1969) A theory of demand for products distinguished by place of production. IMF Staff Papers 16(1):159-178

Central Statistical Agency (2014) Ethiopia Time Use Survey 2013: Main Report. Addis Ababa

Cook J, Masuda Y, Fortmann L, Gugety MK, Smith-Nilson M (2013) How Does Improving Access to Rural Water Supply Change Household Time Use in Ethiopia? Draft January 2013. Seattle

Flaig D (2014) Factor Mobility and Heterogeneous Labor in Computable General Equilibrium Modeling Dissertation Submitted in Fulfilment of the Requirements for the Degree 'Doktor der Agrarwissenschaften.' Universität Hohenheim

Fontana M, Wood A (2000) Modeling the Effects of Trade on Women, at Work and at Home. World Dev 28(7):1173-1190

Gaia Consulting Oy, Ethio Resource Group (2012) Improved Cook Stoves: Final Report, GHG Mitigation and Sustainable Development Through the Promotion of Energy Efficient Cooking in Social Instituitions in Ethiopia. Helsinki

Hutton G, Rehfuess E, Tediosi F, Weiss S (2006) Evaluation of the costs and benefits of household energy and health interventions at global and regional levels. WHO, Geneva

International Energy Agency (2014) Africa Energy Outlook: A Focus on Energy Prospects in Sub-Saharan Africa. World Energy Outlook Special Report, Paris

McDonald S (2007) A Static Applied General Equilibrium Model: Technical Documentation STAGE Version 1: July 2007 Draft. Oxford

Mosa A (2018) Non-agricultural activities and household time use in Ethiopia: a computable general equilibrium model analysis. PhD Dissertation. University of Hohenheim, Stuttgart

Rehfuess E, Mehta S, Prüss-Üstün A (2006) Assessing household solid fuel use: multiple implications for the millennium development goals. Environ Health Perspect 114(3):373-378

Tafere K, Taffesse AS, Tamru S (2010) Food Demand Elasticities in Ethiopia: Estimates Using Household Income Consumption Expenditure (HICE) Survey Data (No. 011). Addis Ababa

Tebekew T, Amoge A, Teferra B, Seyoum Z, Amha M, Beyene H, Fisseha E, Tsehaye E, Ahmed H, Robinson S, Willenbockel D, Dorosh P, McDonald S (2009) Ethiopia Input Output Table and Social Accounting Matrix. Addis Ababa

WHO, UNICEF (2010) Rapid assessment of drinking-water quality in the federal democratic republic of Ethiopia: country report of the pilot project implementation in 2004-2005. WHO, UNICEF, Geneva

WHO, UNICEF (2015) Progress on sanitation and drinking water: 2015 update and MDG assessment. WHO, Geneva

World Bank (2016) Ethiopia public expenditure review. World Bank, Washington

World Health Organization (2012) Global costs and benefits of drinking water supply and sanitation interventions to reach the MDG target and universal coverage (No. 12. 01). World Health Organization, Geneva

\section{Publisher's Note}

Springer Nature remains neutral with regard to jurisdictional claims in published maps and institutional affiliations.

\section{Submit your manuscript to a SpringerOpen ${ }^{\odot}$ journal and benefit from:}

- Convenient online submission

$\checkmark$ Rigorous peer review

- Open access: articles freely available online

- High visibility within the field

- Retaining the copyright to your article

Submit your next manuscript at $\boldsymbol{\nabla}$ springeropen.com 